\title{
High Rise Buildings. The Challenge of a New Field of Possibilities for the use of Structural Concrete
}

\author{
Corres, H.; Romo, J.; Romero, E. \\ FHECOR Ingenieros Consultores
}

ABSTRACT. In this paper, the design and construction of several buildings of moderate height (no more that $250 \mathrm{~m}$ ) are analyzed. In all these projects structural concrete has been used for different elements: floorings, special steel-concrete composite columns using high performance concrete, Shear walls, stiffening floors, etc.

\section{INTRODUCTION}

During the last decades of the $\mathrm{XX}^{\text {th }}$ Century and what has transpired of the $\mathrm{XXI}^{\text {st }}$ Century, a new and exciting explosion in the design and construction of High Rise Buildings has taken place. The speed with which the height of buildings is growing has greatly increased in the last decades. While the maximum height attained during the $\mathrm{XX}^{\text {th }}$ Century was of the order of $500 \mathrm{~m}$, during the next years this value is likely to be more than doubled with credible projects achieving heights of about $1200 \mathrm{~m}$. Concrete, with its new performance features, presents itself as an ideal material in view of solving some of the problems of this type of constructions, especially for medium height structures. $f i b$ is about to form a new Task Group in order to bring together the experience gathered in the last few years and study the new challenges involved in the use of structural concrete for this type of structures.

In Madrid, the construction of four towers of about $250 \mathrm{~m}$ of height designed by Norman Foster, Ribio \& Alvarez-Salas, Cesar Pelli and Pei is reaching its conclusion. In all of them structural concrete in several different varieties has been widely used. These varieties include concrete poured on site and prefabricated, normal density concrete of several characteristic strengths and lightweight concrete, concrete of normal workability conditions and self-compacting, reinforced, prestressed, pre and post-tensioned with bounded and un-bounded strands. Finally concrete has also been used in very different composite steel-concrete elements.

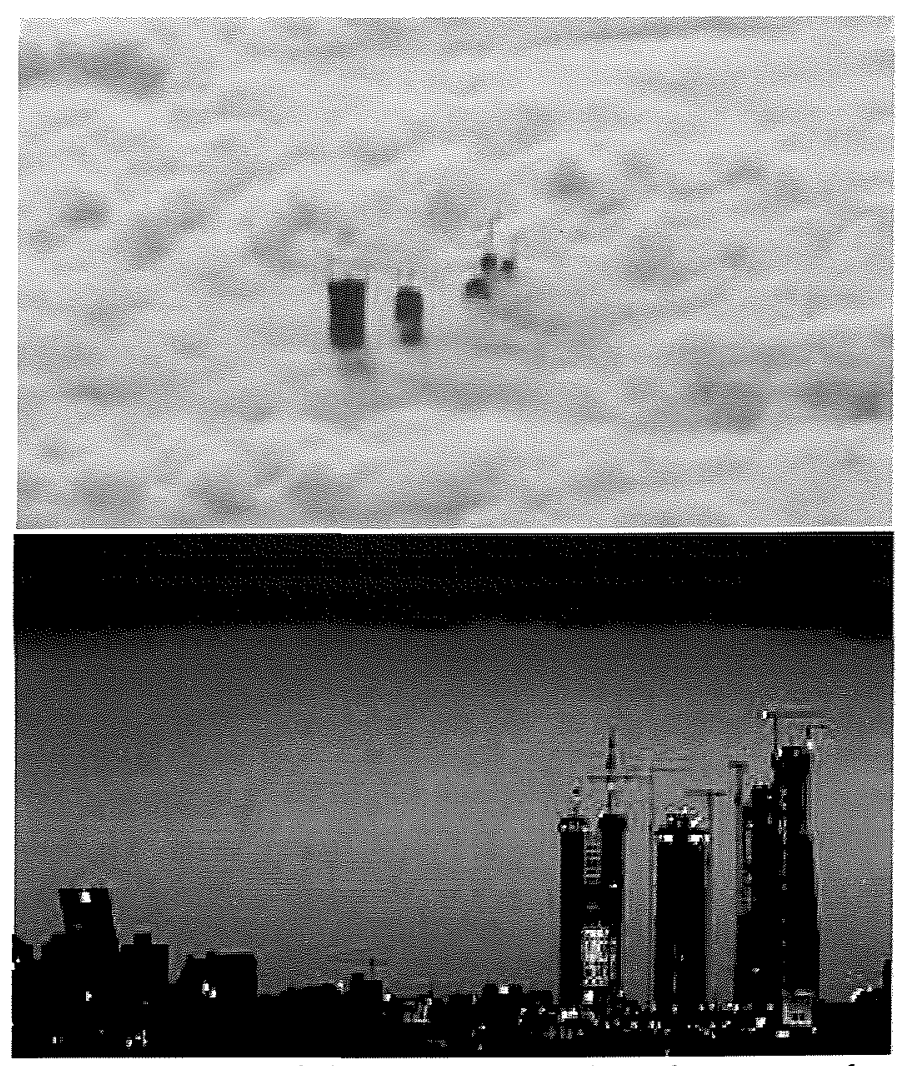

Figure 1 - Views of skyscrapers presently under construction in Madrid 
2 USE OF STRUCTURAL CONCRETE IN DIFFERENT STRUTCURAL MEMBERS

\subsection{Foundations}

The foundations of high-rise buildings have generally been solved using structural concrete. The new possibilities of concrete offer new alternatives. The concreting of members with very dense reinforcement can best be solved by the use of selfcompacting concrete. The use of prestressing allows the transmission of very large concentrated loads which are present in some areas of foundation slabs. Prestressing is also used in pile cups of deep foundations with a large number of piles or very large pile diameters.

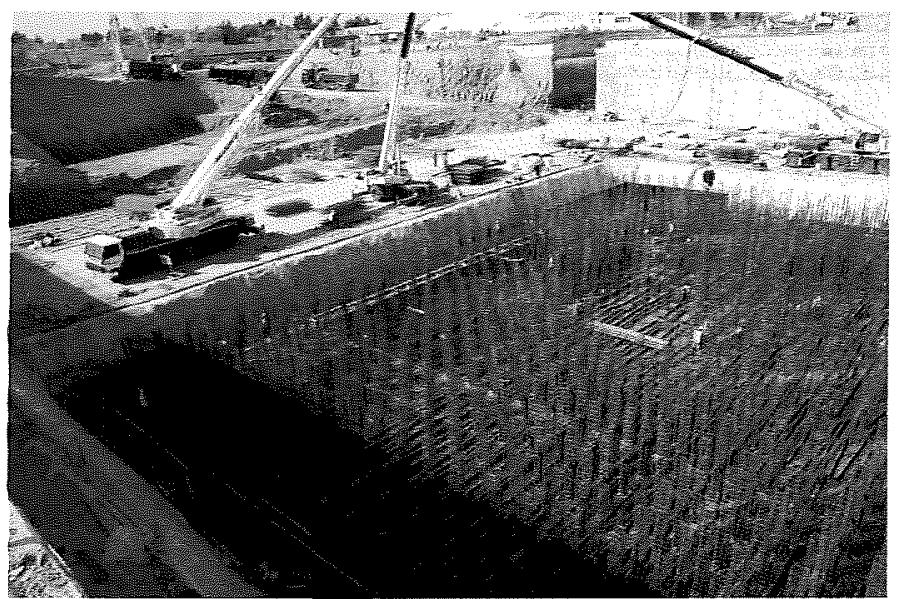

Figure 2 - Foundation slabs of the Torre de Cristal (Glass Tower) in Madrid

\subsection{Vertical Elements}

In most of the towers built in Madrid, composite columns of great capacity located at the building perimeter have been used.

In the perimeter columns of the Torre de Cristal (Glass Tower), which are working mainly as compression members, a composite cross-section with a constant diameter of $0,95 \mathrm{~m}$ has been used. The column is filled with self-compacting C-45 grade concrete and reinforced with steel profiles of decreasing area as height increases. In the lower floors, steel profiles of type HD with HISTAR S 460 steel and varying thickness of up to $120 \mathrm{~mm}$ were used.

Due to the unusually large thickness of the profiles and to the need to speed up constructions, the profiles are considered solely as compression members working by contact. In order to resist tension forces due to local bending, only the resistance of ordinary reinforcement bars was considered.

From the point of view of construction, it became necessary to devise a coupling system for the successive columns fragments which would guarantee conditions of flatness and perpendicularity in order to minimize the contact problems between two successive column fragments. The steel profiles were built in fragments spanning three floors and were lifted into position with the reinforcement already in place. Self compacting concrete was important in order to minimize concreting problems, given the great density of reinforcement and the presence of the steel profile. In this case the required concrete strength was not very high $(\mathrm{C}-45)$. In some of the other towers, with composite columns but with smaller profiles, the strength of concrete decreased with height.

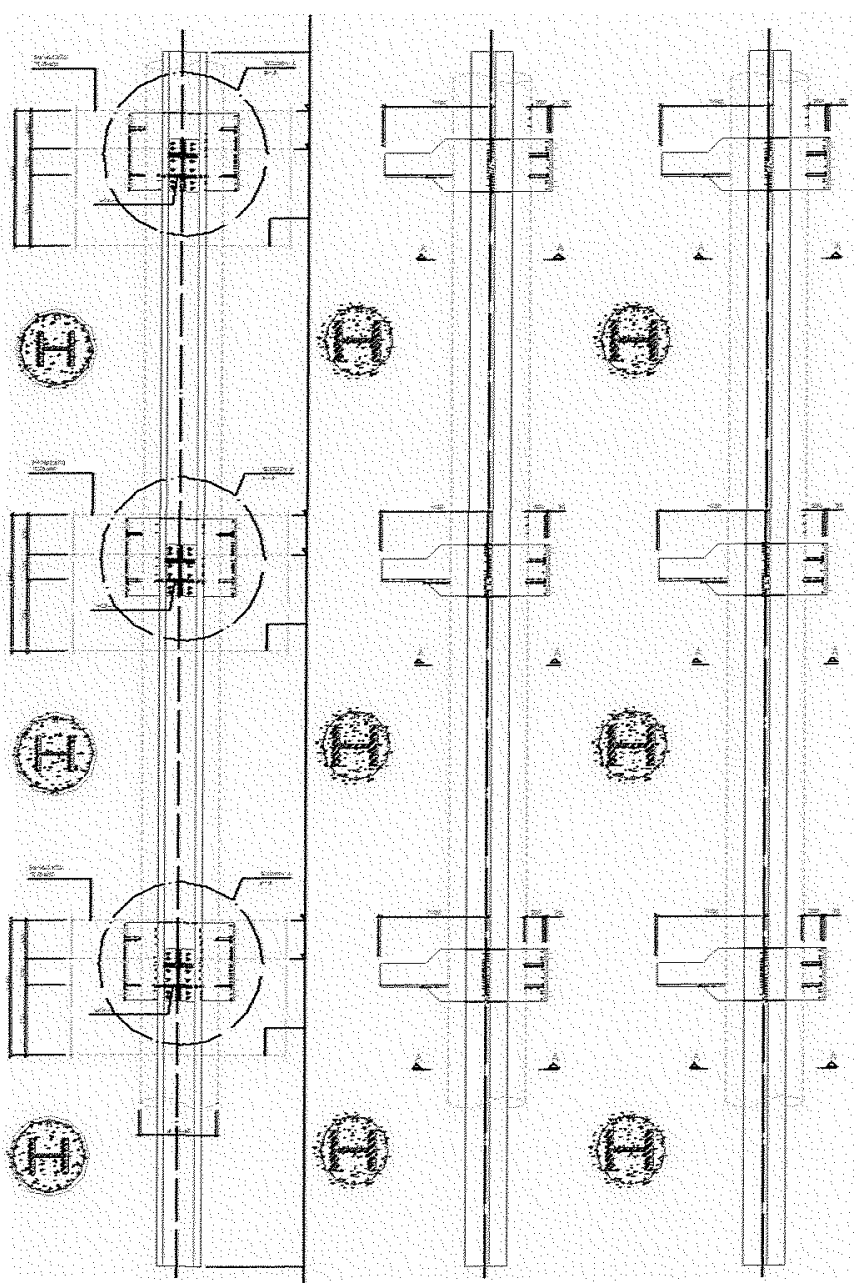

Figure 3 - Plan view of the structure of the Torre de Cristal with a total height of $250,00 \mathrm{~m}$. Cross section of the composite columns.

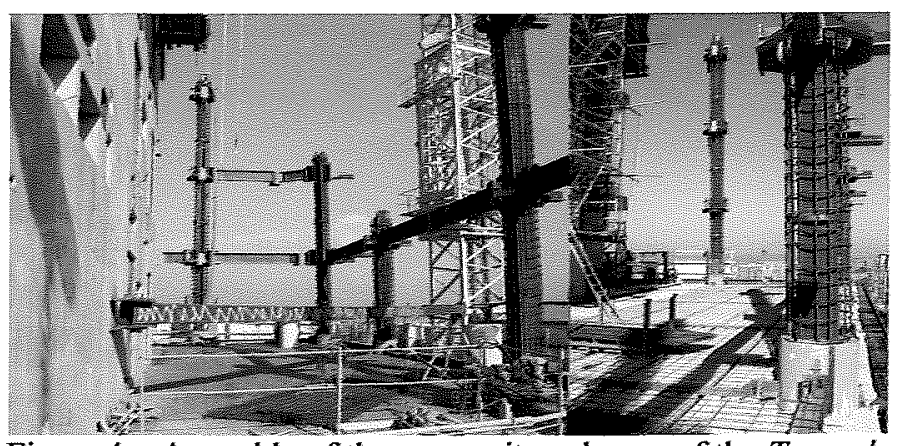

Figure 4-Assembly of the composite columns of the Torre de Cristal 


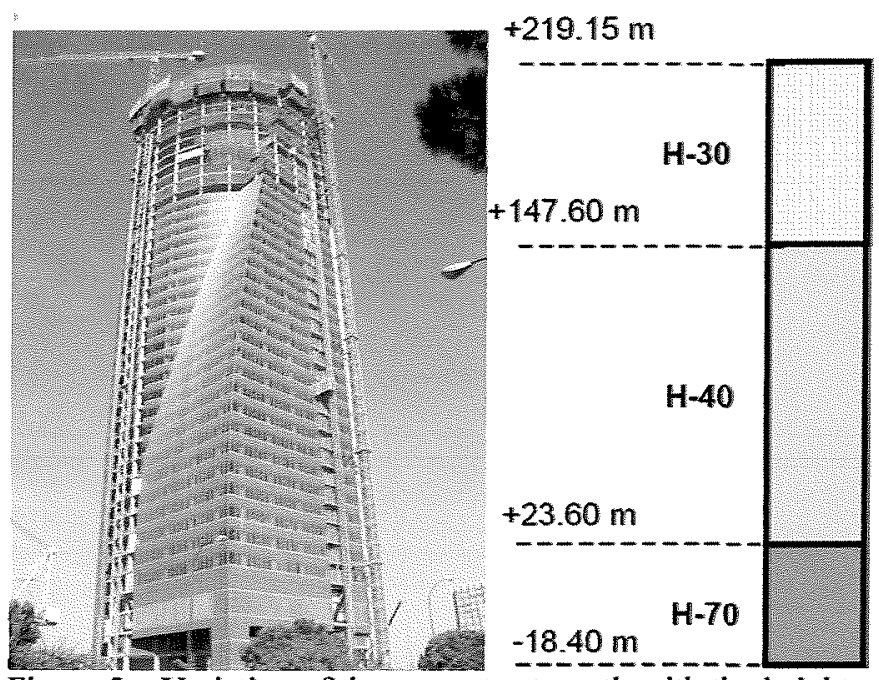

Figure 5 - Variation of the concrete strength with the height of the tower in Torre Espacio [2]

The use of composite columns with high strength concrete minimizes the effect of the differential vertical displacement between the supports and the central nuclei. Structural steel reduces time dependent strains of concrete and high strength concrete has per se smaller time dependent strains than conventional concrete. This design therefore results in a reduction of the difference in vertical displacements between the columns located along the building perimeter and the stiffening nuclei.

\subsection{Floors}

In the present time, the possible solutions for the floors are many. In the Madrid towers almost all possible types have been used.

In the Sacyr - Vallehermoso tower and the Caja de Madrid tower, one of the more classical systems involving a composite floor deck with light weight concrete has been used.

In the Torre de Cristal an original system involving a composite horizontal structure coupled with prefabricated hollow-core slabs was designed. This solution was adopted because the available elevation means were compatible with the placing of the hollow core slabs and because it was decided that this solution would increase construction speed. With this system one floor could be built within one week.

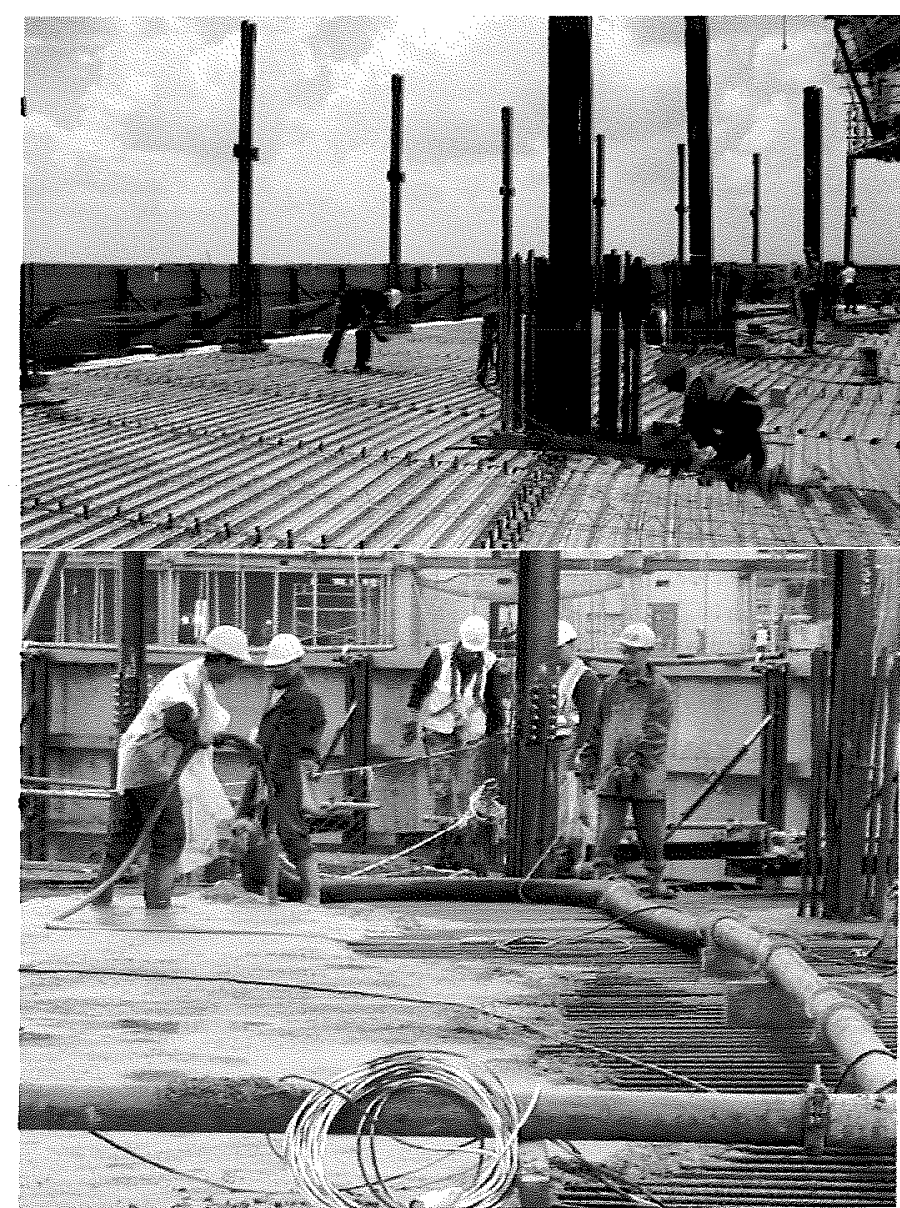

Figure 6 - Composite steel deck with lightweight concrete solution for the floor structure. Sacyr-Vallehermoso tower [2]

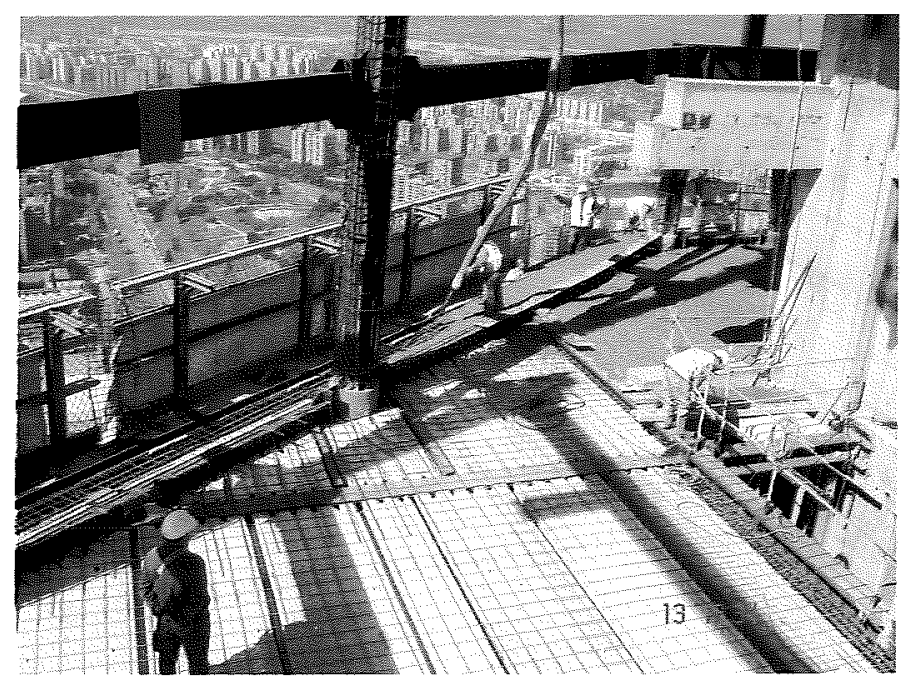

Figure 7 - Hollow core slab solution for the floor structure. Torre de Cristal

In the Torre Espacio, the floor structure was solved using post-tensioned concrete slabs with unbounded prestressing strands. This solution is specially indicated when the shape of the floors cannot be easily solved using a horizontal steel structure. When using a prestressed slab system it is very important to solve well the connection between the support which is made with a high strength concrete and the slab whose concrete strength is lower. 

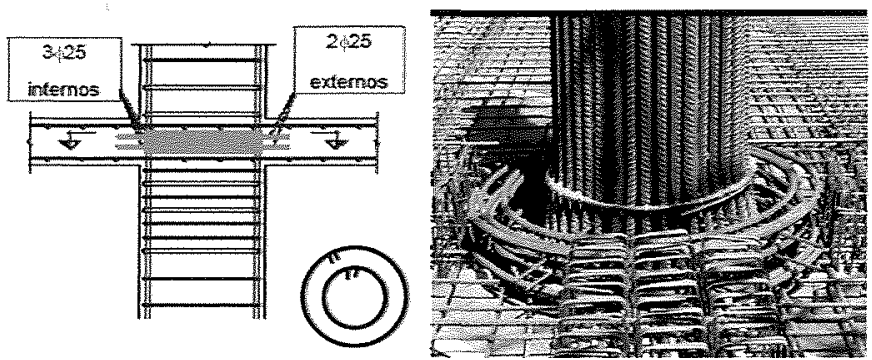

Figure 8-Solution with prestressed slabs, Torre Espacio [2]

In this case this problem has been solved by using confined concrete in slab near the connection with the supports. In this way the confinement increases the concrete strength of the slab and makes it compatible with the strength of the supports.

\subsection{Special members}

The new architectural demands need structural solutions which provide new possibilities for the use of structural concrete.

Figure 9 shows the façade of Torre Espacio whose geometry, as can be seen changes from one floor to the next. This design requires the building of inclined façade supports. The variable inclination has been solved with a change in the inclination of the steel casing of the columns at the floor levels. The resulting horizontal force components are transmitted to the floor structure by prestressing located within the slab.

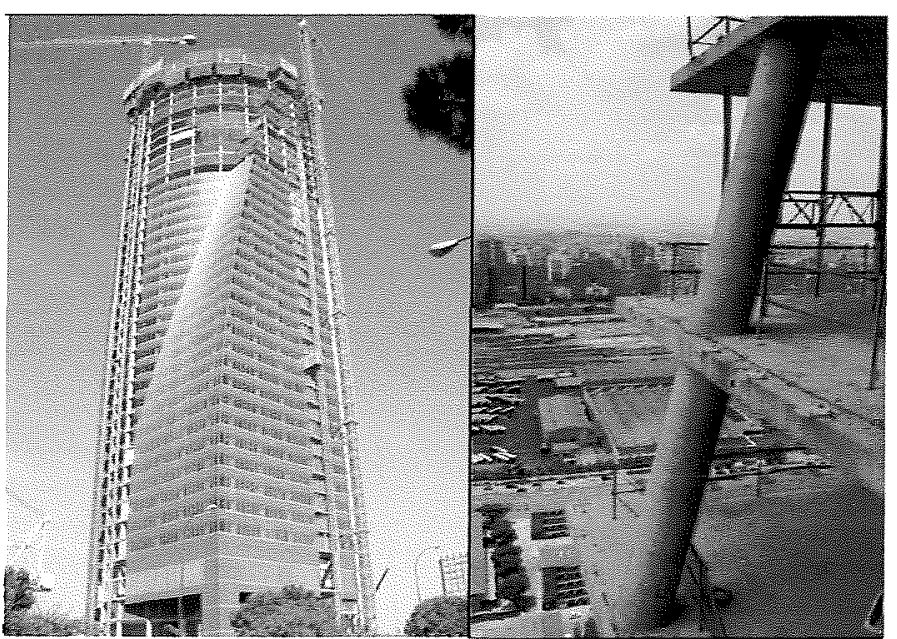

Figure 9. Inclination of the façade columns of Torre Espacio and balancing of horizontal components by means of prestressing integrated in the slabs.

In this type of buildings, very often in the lower floors in which the loads carried by the supports are larger, it is necessary to provide transition elements due to discontinuation of columns. In the case of Torre Espacio this situation is present in the lobby area and has been solved with a composite truss having a height equivalent to that of one floor. The upper and lower chords are composite elements integrated within the floor slabs. The struts and ties of the web are steel boxes filled with concrete. In the case of the vertical struts, subject to compression, the concrete filling has the double role of stabilizing the steel plates and increasing the strength. In the case of the diagonal ties, the composite steel boxes are prestressed in order to increase their bearing capacity in tension.

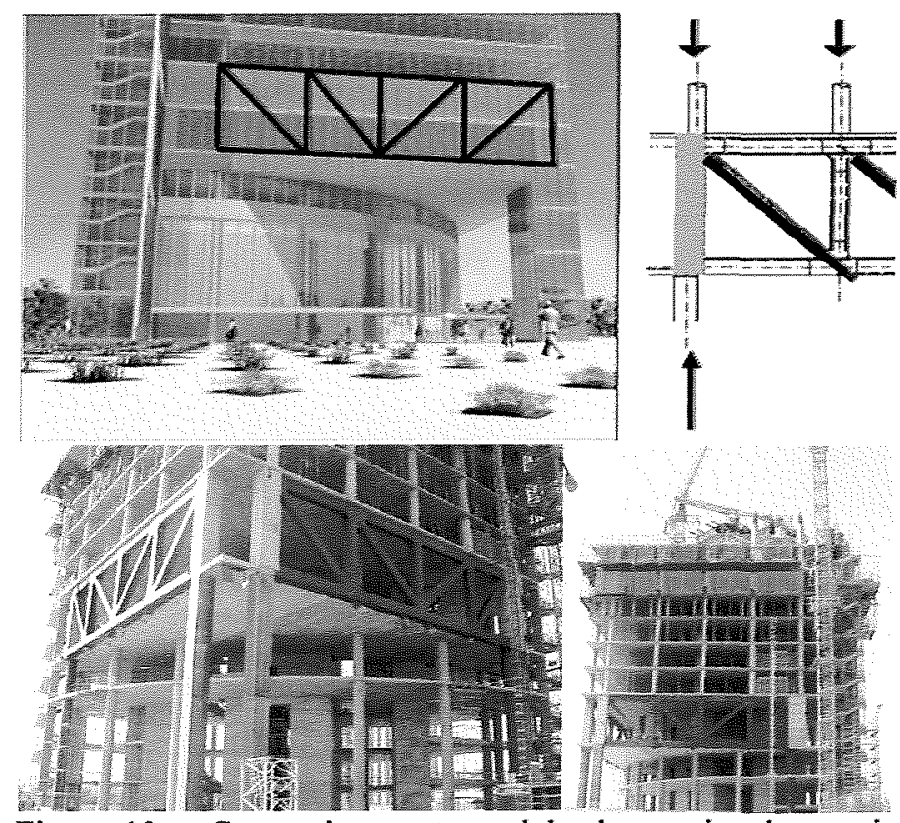

Figure 10 - Composite prestressed load spanning beams in Torre Espacio [2]

In order to increase the efficiency of the vertical walls in resisting horizontal forces such as those due to wind actions, the designing of stiffening floors is a common practice. Stiffening floors work together with compressed and decompressing columns forming a very efficient stiffening system. These stiffening members are usually located in floors containing building installations and can be prestressed elements such as those used in Torre Espacio.

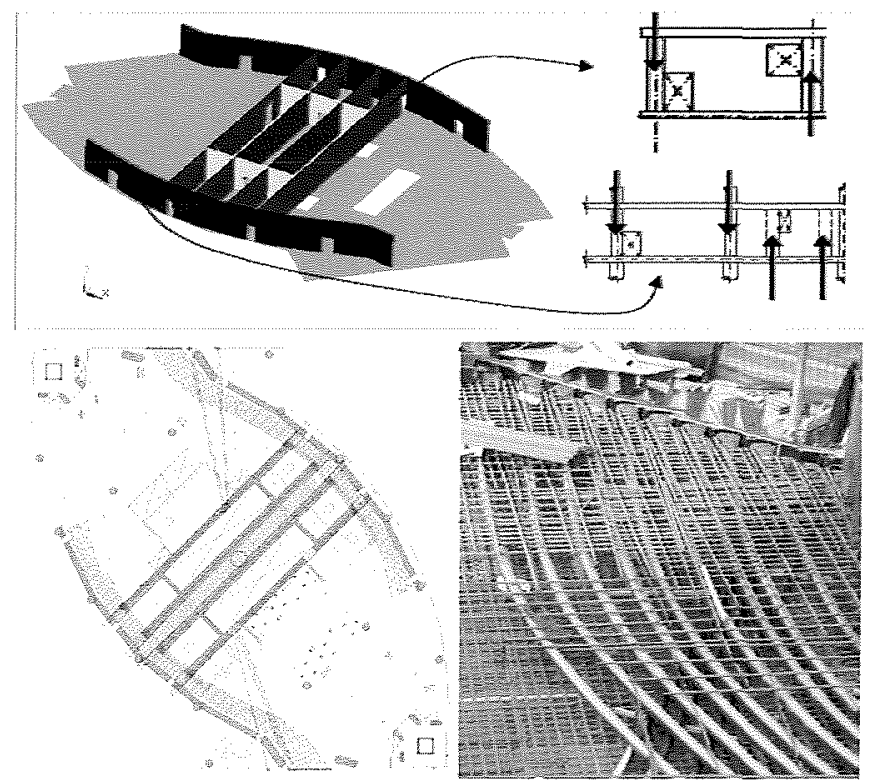

Figure 11 - Elements in transition floors used for lateral stiffening [2] 


\section{FINAL REMARKS}

The new possibilities of concrete from the point of view of strength, technology and construction demand a review of possible applications of this material in all existing structural typologies and also, of course, in high rise buildings.

The adequate, intelligent and creative use of the new concretes is widely extending the field of application of this material and is opening new design possibilities unexplored until now.

\section{BIBLIOGRAPHY}

[1] GÓMEZ NAVARRO, M. Proyecto y construcción de dos torres de $235 \mathrm{~m}$ de altura en Madrid: Similitudes y diferencias entre estructura mixta y estructura de hormigón. XVII Curso Master CEMCO. Jornada J5: ACHE y el hormigón estructural. Instituto Eduardo Torroja. Madrid, 15 de junio de 2007.

[2] Gómez Hemoso, J. Proyecto y construcción de edificios altos. XVII Curso Master CEMCO. Jornada J5: ACHE y el hormigón estructural. Instituto Eduardo Torroja. Madrid, 15 de junio de 2007.

[3] Romo Martín, J. Cargas horizontales - edificios en altura. Curso de Especialidad en Cálculo Estructural: Concepción Estructural del Edificio. Máster en Estructuras de la Edificación. 